\title{
First report of leopard fossils from a limestone cave in Kenting area, southern Taiwan
}

\author{
Tzu-Chin Chi ${ }^{\text {Equal first author, 1, } 2, \text { Yi Gan }}{ }^{\text {Equal first author, } 3}$, Tzu-Ruei Yang ${ }^{\text {Corresp., 1, } 3}$, Chun-Hsiang Chang ${ }^{\text {Corresp. } 1}$ \\ 1 Department of Geology, National Museum of Natural Science, Taichung, Taiwan \\ 2 Department of Earth and Environmental Sciences, National Chung Cheng University, Chiayi, Taiwan \\ 3 Department of Earth Sciences, National Cheng Kung University, Tainan, Taiwan \\ Corresponding Authors: Tzu-Ruei Yang, Chun-Hsiang Chang \\ Email address: tzurueiyang@nmns.edu.tw, cch@nmns.edu.tw
}

Longshia-dong Cave, a limestone cave located in the Kenting area within the Kenting National Park of southern Taiwan, yields numerous terrestrial mammalian fossils. Many of them were not reported in historical literature and are neither present in Taiwan. For instance, no historical literature mentioned leopards inhabited in Taiwan, and thus their existence remained unknown. This study describes three fossil leopard (Panthera pardus) teeth uncovered from Longshia-dong Cave. Two isolated lower premolars and one lower molar, respectively p3, p4 and $\mathrm{m} 1$, were discovered in a very small area $(11 \times 6 \mathrm{~cm})$ and show a series of progressive increase in size. Thus, the three teeth should have been belonging to the same individual from the subfamily of Pantherinae. Traditional linear measurements and two-dimensional geometric morphometric analysis for the occlusal surface outlines were conducted on the fossil teeth and extant pantherines inhabited in Asia such as clouded leopards (Neofelis nebulosa), leopards (Panthera pardus), and tigers (Panthera tigiris). Results show that the fossil teeth are similar both in size and morphology to the teeth of extant leopards, suggesting the assignment of the fossil teeth to leopards. This study, for the first time, reported the presence of leopards in the Late Pleistocene of Taiwan. Besides, the smaller size of the fossil teeth than Chinese fossil leopards is putatively attributed to insular dwarfism or individual size variability, yet more studies are required. 


\section{First report of leopard fossils from a limestone cave in}

\section{Kenting area, southern Taiwan}

5

6 Tzu-Chin Chi ${ }^{1,2}$, Yi Gan ${ }^{3}$, Tzu-Ruei Yang ${ }^{1,3}$, Chun-Hsiang Chang ${ }^{1}$

9 1. Department of Geology, National Museum of Natural Science, 404605 Taichung, Taiwan

2. Department of Earth and Environmental Sciences, National Chung Cheng University, 621301 Chiayi County, Taiwan

3. Department of Earth Sciences, National Cheng Kung University, 701401 Tainan, Taiwan

14 Corresponding Authors:

15 Tzu-Ruei Yang

16 No. 1, Guanqian Rd., North Dist., Taichung City 404605, Taiwan

17 Email address: tzurueiyang@nmns.edu.tw

18 Chun-Hsiang Chang

19 No. 1, Guanqian Rd., North Dist., Taichung City 404605, Taiwan

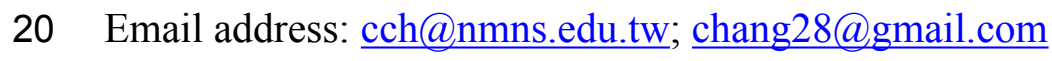

21

22

Keywords: Felidae, Morphology, Panthera pardus, Late Pleistocene, Geometric morphometric analysis 


\section{Abstract}

27 Longshia-dong Cave, a limestone cave located in the Kenting area within the Kenting National

28 Park of southern Taiwan, yields numerous terrestrial mammalian fossils. Many of them were not 29 reported in historical literature and are neither present in Taiwan. For instance, no historical

30 literature mentioned leopards inhabited in Taiwan, and thus their existence remained unknown.

31 This study describes three fossil leopard (Panthera pardus) teeth uncovered from Longshia-dong

32 Cave. Two isolated lower premolars and one lower molar, respectively p3, p4 and m1, were

33 discovered in a very small area $(11 \times 6 \mathrm{~cm})$ and show a series of progressive increase in size.

34 Thus, the three teeth should have been belonging to the same individual from the subfamily of

35 Pantherinae. Traditional linear measurements and two-dimensional geometric morphometric

36 analysis for the occlusal surface outlines were conducted on the fossil teeth and extant

37 pantherines inhabited in Asia such as clouded leopards (Neofelis nebulosa), leopards (Panthera

38 pardus), and tigers (Panthera tigiris). Results show that the fossil teeth are similar both in size

39 and morphology to the teeth of extant leopards, suggesting the assignment of the fossil teeth to

40 leopards. This study, for the first time, reported the presence of leopards in the Late Pleistocene

41 of Taiwan. Besides, the smaller size of the fossil teeth than Chinese fossil leopards is putatively

42 attributed to insular dwarfism or individual size variability, yet more studies are required.

\section{Introduction}

45 Longshia-dong Cave (= Lobster Cave) is located in the Kenting Forest Recreation Area 46 (KFRA) of the Kenting National Park, southernmost Taiwan (Fig. 1). The KFRA is covered with 47 thick limestone (Hengchun Limestone) that deposited during the Middle Pleistocene (Gong \& 
48 Yui, 1998). A number of caves and fissures formed in the Hengchun Limestone, some of which,

49

50 51 (Kawamura et al., 2016).

52 the present one. knowledge. such as Longshia-dong Cave, accumulated numerous terrestrial mammal fossils. This cave opens at ca. $240 \mathrm{~m}$ above the present sea level and is a small tunnel inclined gently toward its inner part

The investigation of Longshia-dong Cave was initiated by Prof. Yoshinari Kawamura from the Aichi University of Education, Japan and Dr. Chun-Hsiang Chang from the National Museum of Nature Science, Taiwan (Kawamura et al., 2016). To date, fossils of Cervidae, Rodentia (e.g., Microtus and Hystrix), Carnivora (three teeth; this study), Macaca sp., and Rhinolophus sp. uncovered from this cave are identified (Kawamura et al., 2016). However, the Microtus (Rodentia) is now restricted to high mountains in Taiwan and the Hystrix sp. (Rodentia) is no longer present in Taiwan. Besides, leopard teeth were not reported in Taiwan previously. These lines of evidence indicate a very different faunal setting in comparison with

In previous excavations scientists have discovered putative Middle-Late Pleistocene big cat fossils, such as Panthera cf. tigris and Panthera sp. from the Chochen area in southern Taiwan (Fig. 1; Otsuka, 1984; Chen, 2000a; Chen, 2000b; Wei, 2007). Besides, fossil remains of Panthera tigris have also been collected from the Penghu Channel, a N-S striking submarine valley off the west coast of Taiwan (Fig. 1) (Ho et al., 1997; Asahara et al., 2015). While both of these studies indicate a rich fossil record of felids in the Middle-Late Pleistocene of Taiwan, the modern Felidae in Taiwan are only featured by two species, including clouded leopard (Neofelis nebulosa) and leopard cat (Prionailurus bengalensis). Even more recently, Chiang et al. (2015) presumed that the former is extinct in Taiwan, thus leaving only the latter present to our 
71 Previous studies indicated the similarities of Taiwan's fauna to the Early Pleistocene fauna 72 of southern China (e.g., Otsuka \& Lin, 1984; Lai, 1989; Qi et al., 1999; Chen, 2000a; Fooden \& $73 \mathrm{Wu}, 2001)$. The fauna of southern China probably entered Taiwan in the Late Pliocene to Early

74 Pleistocene, when Taiwan was connected with China (Lai, 1989; Chen, 2000a; Fooden \& Wu, 75 2001); however, only clouded leopard was reported in Taiwan's historical record. While 76 Swinhoe (1862) had never seen a living individual, he described it as a small, short-tailed, small77 footed animal based on the fur specimen and named it as Leopardus brachyurus. Later, Swinhoe 78 (1870) replaced L. brachyurus with Felis macrocelis, but L. brachyurus is still the most 79 commonly used name.

80 In the excavation to Longshia-dong Cave in 2014, three teeth were collected from the same 81 horizon. A preliminary study has indicated their affinity to feline remains, though further 82 investigations are needed (Gan, 2016). This study thus aims to reveal their taxonomic affinity 83 based on traditional linear and geometric measurements. Besides, the comparison between the 84 studied material and leopard fossils from various sites of the Pleistocene in China, including the 85 Zhoukoudian site (Teilhard de Chardin \& Pei, 1941) and Mentougou Bull Eye Cave (Deng et al., 86 1999) of Beijing, Lantian (Gongwangling) of Shanxi (Hu \& Qi, 1978), Anyang (Yinxu) of 87 Henan Province (Teilhard de Chardin \& Young, 1936), Liucheng Cave of Guangxi Province 88 (Pei, 1987), also allows us to reveal more details.

89 Geological setting

90 The Kenting National Park is located in the Hengchun Peninsula, southernmost Taiwan 91 (Fig. 1). The Hengchun Peninsula represents the earliest stage of the Taiwanese orogeny (Huang 92 et al., 1985), and therefore many incipient thrust faults are observed. A major boundary fault, the 93 N-S striking Hengchun Fault (Fig. 1; Chen et al., 2005), divides the Hengchun Peninsula into 
94 two terranes, including the Central Range in the East and the Western Foothills (Hengchun

95 Valley and West Hengchun Hill) in the West (Yen \& Wu, 1986). Since the Late Pleistocene, the

96 Hengchun Peninsula was uplifted at a rate of 2-6 mm/yr (Chen et al., 2005) and thus gave rise to

97 the development of coral reef and limestone (Hengchun Limestone). Many karst caves were

98 afterward formed and harbor various fossils. A thin layer of reddish sand and gravels (Hsu, 1989;

99 Hseu et al., 2004) overlying the Hengchun Limestone was named as Eluanpi Bed in the

100 Southeast, or Taiping Formation in the West, to Longshia-dong Cave (Fig. 1).

101 Our studied area, Longshia-dong Cave, is located in the southeastern part of the Kenting

102 National Park, a national park that is featured by the karst landscape mostly contributed by the

103 Hengchun Limestone (Fig. 1). The cave opens to the East, measuring 30 40 m long, $8 \mathrm{~m}$ wide,

104 and about $5 \mathrm{~m}$ deep, and a puddle was found in the end of the cave (Kawamura et al., 2016).

105 Most of the limestone in the cave is covered by a layer of reddish sediment composed of

106 limestone pebbles and fossils, though the boundary between the reddish sediment and Hengchun

107 Limestone is unclear. A flow stone made of carbonate calcite was found $7 \mathrm{~m}$ away from the cave

108 entry, and the fossil-bearing sediments are found behind it. The fossil-bearing sediments are

109 characterized by a mixture of reddish sand and mud, as well as limestone pebbles, which shows a

110 great similarity to the Eluanbi Bed. Besides, a layer of blackish mud and light yellowish-red silt

111 (possibly loess) overlying the fossil-bearing sediments, based on a previous study using ${ }^{14} \mathrm{C}$

112 dating, is composed of recent alluvial deposits since the Holocene (Wang, 2015).

113 Since an estimation of the age for the fossil-bearing sediments was inaccessible, previous

114 studies have put emphasis on the age of formation of the Hengchun Limestone, which gave a

115 maximum estimation for the leopard fossils uncovered from the cave. The Hengchun Limestone

116 was either considered two-stage (Gong, 1982) or three-stage (Shih et al., 1989) reef formation, 
117 but both studies have concluded a dating result of $500 \mathrm{ka}$, which is similar to the result arisen

118 from nannofossils (NN19, around $500 \mathrm{ka}$; Chi, 1982). Besides, another geochemical

119 chronological study has suggested a date of 325-125 ka for the age of formation of the Hengchun 120 Limstone (Gong, 1994).

121 Afterwards, Kawamura et al. (2016) offered the first estimation of the age for the fossil122 bearing sediments. Based on stratigraphic relationships, Kawamura et al. (2016) suggested an 123 age of the Late Pleistocene (126 to $12 \mathrm{ka}$ ) for the fossil-bearing sediments, which is much older 124 than the $7 \mathrm{ka}$ revealed by ${ }^{14} \mathrm{C}$ dating of the bone collagen extracted from some ruminant antlers 125 and lower jaws uncovered from the same locality. Because of the rarity and poor-preservation of 126 the leopard remains in this study, a rigorous age of the leopard remains is inaccessible. While the 127 age of the fossils requires further investigations, this study will discuss further details of the 128 leopard remains based on the temporal range from 500 to $12 \mathrm{ka}$.

\section{Materials \& Methods}

Three well-preserved whitish fossil teeth were collected from Longshia-dong cave in the 2014 excursion led by one of the authors (C.-H. Chang). All of them (F056584, F056585, and F056586) are housed at National Museum of Natural Science, Taichung, Taiwan (NMNS) under the accession numbers provided. Before excavation, we used strings to divide the cave ground into a grid contributed by mostly $50 \times 50 \mathrm{~cm}$ areas. The three teeth were discovered in a small portion $(11 \times 6 \mathrm{~cm})$ out of one of the areas and present a series of progressive increase in size; teeth, based on their shape (Hillson, 2005), are assignable to p3 (F056584), p4 (F056585) and 
140 mandibles of 17 extant specimens, including seven clouded leopards (Neofelis nebulosa, but one 141 of them might be Sunda clouded leopard (Neofelis diardi)), five leopards (Panthera pardus), and

142 five tigers (Panthera tigris), which are housed at the NMNS, Endemic Species Research

143 Institute, and Taipei Zoo, respectively, were also included in this study (see the details in the

144 Supplemental Tab. 1). Prior to our qualitative studies of the fossil and extant felid teeth

145 (Kawamura, 1992; Fukawa, 2000), we compare their morphological features to determine the

146 assignment of the fossil felid teeth (Fig. 3). Photos of all specimens were taken with a Panasonic

147 Lumix DMC-GF1 camera and a Panasonic Lumix GF1 14-45mm/F3.5-5.6 lens. For the

148 traditional linear measurements and geometric morphometric studies, these photos were

149 afterwards imported into the tpsDig 2.05 (Rohlf, 2005).

150 Traditional linear measurements were taken point-to-point; a total of 22 dental dimensions

151 including antero-posterior crown length (1, 5, 15 in Fig. 4), dorsoventral crown height (3, 7, 10,

152 13, 17, 20 in Fig. 4), width of each cusp (4, 8, 11, 14, 18, 21 in Fig. 4), anteroposterior length of 153 cusps $(2,6,9,12,16,19$ in Fig. 4), and crown height at the place of carnassial notch (22 in Fig.

154 4) (Christiansen, 2008), were obtained from all specimens if accessible (a fossil individual and

15517 extant specimens, see the details in the Supplemental Tab. 1). The three fossil felid teeth

156 belonged to the right mandible and therefore 22 dental dimensions were obtained. The 17 extant

157 specimens, on the other hand, permit the measurement of both lower right and left jaws, thus

158 contributing to a $17 \times 22 \times 2$ data matrix (note that some dental dimensions are not available due to

159 poor preservation, see the details in the Supplemental Tab. 1).

160 The data from the aforementioned traditional linear measurements were introduced into two

161 rounds of principal component analysis (PCA) (Morrison, 1976; Dunteman, 1994), which plots

162 the data to a new coordinate system. The new coordinate system is contributed by $\mathrm{N}-1$ principal 163 components, which are orthogonal to each other (Jolliffe, 2002; Hsu, 2003). All PCA in this 
164 study were performed with the R package "stats" (R Core Team, 2013). In the first round of 165 PCA, 22 dental dimensions from the three teeth (p3, p4, and $\mathrm{m} 1$ ) of a mandible (either right or 166 left) are seen as a dataset. Any missing of the 22 dental dimensions from $\mathrm{p} 3$, $\mathrm{p} 4$, or $\mathrm{m} 1$ leads to 167 the removal of the whole dataset from the first round of PCA. Ultimately, one dataset from the 168 felid fossil, ten datasets from the seven clouded leopards, five datasets from the five leopards, 169 and nine datasets from the five tigers, were used in the first round of PCA (Fig. 5a).

170 To avoid the effect of the interspecific difference in tooth size on the first round of PCA, we 171 performed the second round of PCA with the R package "stats" for $\mathrm{p} 3$, $\mathrm{p} 4$, and $\mathrm{m} 1$, separately. 172 For instance, we obtained three ratios, including of protoconid length (2 in Fig. 4 and Tab. 1) to 173 crown length (1 in Fig. 4 and Tab. 1), of protoconid height (3 in Fig. 4 and Tab. 1) to crown 174 length (1 in Fig. 4 and Tab. 1), and protoconid length (2 in Fig. 4 and Tab. 1) to protoconid 175 height (3 in Fig. 4 and Tab. 1) based on the data from all available p3 (a fossil felid, 13 clouded 176 leopards, five leopards, and nine tigers). The three ratios were used for PCA analysis with the 177 package "stats." For PCA analysis (Fig. 5b), on the other hand, six ratios and seven ratios were 178 obtained based on the data from all available $\mathrm{p} 4$ and m1, respectively (see the details in Fig. 5) 179 and were analyzed with the package "stats" (Figs. 5c and 5d). Besides, we construct a bivariate 180 plot of the selected numbered dimensions of $\mathrm{p} 3, \mathrm{p} 4, \mathrm{~m} 1(1,4,5,11,15,21$ from Tab. 1) of the 181 fossil and extant leopard specimens with the regression lines for each selected number 182 dimensions (Fig. 6).

183 In addition to the PCA analyses based on traditional linear measurements, we also 184 performed geometric morphometric analysis (Slice, 1996) because of its utility of revealing the 185 morphological differences between different groups (Zelditch et al., 1995) and the ability to 186 exclude the factor of size. All photographs were input into the program tpsUtil for building up a 187 tps file. To access the morphology of the occlusal surface of each tooth in the absence of 
188 apparent landmarks, we used the "curve mode" in the program tpsDig 2.05 (accessed on Dec 1, 1892014 from http://life.bio.sunysb.edu/morph/; (Rohlf, 2005) to place evenly distributed 150 semi190 landmarks around the occlusal surface on each photo (Gunz \& Mitteroecker, 2013). The 150 191 semi-landmarks were then digitized from photographs using tpsDig 2.05, which converted the 192 points marked on the photographs into Cartesian x, y coordinates. After scaling and alignment of 193 the digitized semi-landmarks using generalized Procrustes analysis, a relative warp analysis 194 (RWA) was then performed on the set of specimen semi-landmarks in tpsRelw (Rohlf, 2007) to 195 unravel the morphological variation between the fossil and extant teeth. We then visualize the morphological variation from RWA by plotting the relative warp axes as a PCA. Relative differences are presented in the form of thin plate spline deformation grids (Figs. 7-9; Zelditch et al., 2004; Tseng et al., 2010).

\section{Results}

\section{Description and morphological comparison}

Family Felidae Fischer [von Waldheim], (1817)

203

Subfamily Pantherinae Pocock, 1917

204

205

Genus Panthera Oken, 1816

206

Panthera pardus (Linnaeus, 1758) (Fig. 2)

Based on our observation of all extant felid specimens and previous studies (Gray, 1867;

207 Christiansen \& Kitchener, 2011; King, 2012), we concluded the following common dental 208 characters (Fig. 3): (1) two-rooted p3, p4 and m1; (2) p3 is smaller than p4; (3) p4 is in a 209 similar size to $\mathrm{m} 1$; (4) p3, p4 has three cusps (paraconid, protoconid and hypoconid) and its 
210 paraconid and hypoconid are well-developed (5) $\mathrm{m} 1$ has two well-developed cusps (paraconid 211 and protoconid) and undeveloped talonid. All of the aforementioned features are present in the 212 fossil teeth and thus indicate the assignment of the fossil teeth to Felidae. Moreover, the fossil 213 teeth can be further assigned to Pantherinae based on their similar size to extant pantherines.

214 Pumas (Puma concolor), which belong to Felinae, a sister group to Pantherinae, are the only 215 group of felines that present similar dental size; however, their current distribution (only in 216 Americas) makes the attribution of the fossil teeth to puma unlikely.

217 In previous studies (Meachen-Samuels \& Van Valkenburgh, 2009), dental size is the only 218 character that was used for distinguishing different pantherines, such as lions (Panthera leo), 219 snow leopards (Panthera uncia), tigers, clouded leopards, and leopards. For instance, the dental 220 size of lions is significantly larger than the one of the fossil teeth. Moreover, the attribution of 221 the fossil teeth to snow leopards is unlikely since snow leopards are only present in high 222 mountains. However, dental size is not an indicator for the distinguishment between tigers, 223 clouded leopards, and leopards. This study, however, shows that several pantherines, including 224 clouded leopards, leopards, and tigers, can be distinguished based on three dental characters, 225 including (1) the level of p3 paraconid development, (2) the shape of p4 occlusal surface, (3) the 226 size difference between $\mathrm{m} 1$ paraconid and $\mathrm{m} 1$ protoconid (Fig. 3; Tab. 2).

227 Clouded leopards have two distinct features, including an absent paraconid of p3 (as seen in 228 all examined clouded leopards) and a well-developed protoconid of $\mathrm{m} 1$, while both of which are 229 absent in the fossil teeth from Longshia-dong Cave (Fig. 2). Thus, the assignment of the fossil 230 teeth from Longshia-dong Cave to clouded leopards is here excluded. On the other hand, tiger 231 teeth are characterized by a highly developed 4 paraconid, which is not seen in the fossil teeth 232 (Figs. 2, 7). Moreover, the $\mathrm{p} 3$ of tigers has a lower paraconid than the one of the fossil (Figs. 2, 
233 7). Tigers also present a wider crown in all teeth, especially in $\mathrm{m} 1$, than the ones of the fossil 234 (Tab. 2).

235 The fossil pantherine teeth, in addition to their size, show many distinct features that are 236 similar to those of the extant leopards, such as the presence of $\mathrm{p} 3$ paraconid and the shape of 237 occlusal surface. The presence of $\mathrm{ml}$ and slightly worn enamel further indicate that the fossil 238 teeth might belong to a very young adult (Stander, 1997). The presence of hollow, not fully 239 developed roots in the fossil teeth further suggests a juvenile origin (about 1 2 years old).

240 However, the gender of the fossil pantherine is uncertain because of the absence of canine teeth

241 (whose size is a key difference between male and female carnivores), the lacking of

242 morphological differences between male and female leopard teeth (Pocock, 1930), and the 243 extremely poor sample size MNI = 1 (minimum number of individuals).

244 Traditional linear measurement

245 While our aforementioned morphological comparison indicates the affinity of the fossil 246 teeth to leopards (Panthera pardus), traditional linear measurement was performed for further 247 lines of evidence. The result of the first round of PCA based on the 22 dental dimensions shows 248 a significant disparity between tigers and the others (clouded leopards and leopards) (Fig. 5a) 249 (factor loading of each component shows on Supplemental Tab. 3), although the disparity 250 between clouded leopards and leopards is inapparent. In the second round of PCA based on 251 various ratios from the dimensions of $\mathrm{p} 3, \mathrm{p} 4$, and $\mathrm{m} 1$, no pattern is indicated by the result of the 252 PCA on p3 (Fig. 5b) and the fossil teeth is not clustered by any group. However, based on the 253 result of PCA on p4 and $\mathrm{ml}$ (Fig. 5c and 5d), the assignment of the fossil teeth to clouded 254 leopards is excluded. 
While the above PCAs have potentially rules out the affinity of the fossil teeth to leopards,

256

257

258

259

260

261

262

263

264

265

266

267

268

269

270

271

272

273

274

275

276

277 the three fossil teeth were very likely from a common origin. our previous inference that the three fossil teeth belonged to the same individual.

\section{Geometric morphometric analysis}

we further conducted a comparison of the selected dental dimensions including $1,4,5,11,15,21$

(Tab. 1) between the fossil and five extant leopard specimens (Fig. 6). The result shows a similar

covariation of the $\mathrm{p} 3, \mathrm{p} 4$, and $\mathrm{m} 1$ between the fossil and five extant leopard specimens, further supporting

In addition to the traditional linear measurement (Fig. 5), geometric morphometric analysis was also performed for further lines of evidence. In the RWA based on all third premolars (p3), the first three relative warp axes accounted for $74.81 \%$ of the total variation, though no morphological disparities were revealed (Fig. 7). The RWA based on all fourth premolars (p4), however, shows the disparity between clouded leopards and the others in the plots of RW1 to RW2 (Fig. 8a) and RW2 to RW3 (Fig. 8c). The RW2 explains $24.52 \%$ of the total shape variance and relates primarily to the prominence of the mesial side toward buccal or lingual side (Fig. 8f). On the other hand, the RWA based on all first molars indicates the isolation of tigers in the plots of RW1 to RW2 (Fig. 9a) and RW2 to RW3 (Fig. 9c). Striking samely, the RW2 in the RWA based on all first molars, which accounts for $22.67 \%$ of the total variation, is also the best indicator that excludes tigers.In summary, the fossil pantherine teeth uncovered from Longshiadong Cave, based on various lines of evidence, are assignable to leopards. While the plot of p3, $\mathrm{p} 4$, and $\mathrm{m} 1$ sizes of the fossil and extant leopards indicates that only the fossil $\mathrm{m} 1$ is encompassed within the variations of the extant leopard teeth, the slope of the regression line based on the three fossil teeth is similar to the ones of those based on the extant specimens. Thus, 


\section{Discussion}

279

280

281

282

283

284

285

286

287

288

289

290

291

292

293

294

295

296

297

298

299

300

An integrative, qualitative method for the identification of leopard teeth

Morphological comparisons have been utilized in many studies for the species identification of various mammalian teeth, such as elephants (Todd, 2010), hedgehogs (Gould, 2001) and moles (Van Cleef-Roders \& Van Den Hoek Ostende, 2001). Despite the similarity both in size and morphology of pantherine teeth (lions excluded as their teeth are apparently larger than leopard teeth), several studies offered qualitative methods on the basis of the size and morphology for the identification of the subfamily of Pantherinae (e.g., Hemmer, 1966). On the other hand, canid teeth are much more complex than felid teeth and thus have more homologous features for landmarks. Therefore, Asahara et al. (2015) have applied morphological comparisons in combination with geometric morphometric analyses to canine teeth, which is an integrative method that has never been performed on felid teeth. This study, for the first time, demonstrates that an integration of morphological comparisons, linear measurements, and geometric morphometric studies allows species identification of the subfamily of Pantherinae based on teeth. Based on the integrated approach, we thus assign the studied fossil teeth (F056584, F056585, and F056586) to Panthera pardus.

\section{Taphonomic implications for an adult origin of the fossil teeth}

A previous study by Stander (1997) suggested that tooth wear in leopards is a reliable indicator for their ages. The eruption of permanent teeth in one to two years old leopards is completed and thus are whitish and wearless. The crown tips are worn in individuals older than

three years old, and the tooth wear appears first on incisors, then on canines, on premolars, and finally on molars. The wear is apparent on the teeth of the individuals of five or six years old. Although the fossil teeth in this study only preserve $\mathrm{p} 3, \mathrm{p} 4$, and $\mathrm{m} 1$, their complete eruption 
301 indicates an age older than one year. Moreover, the slight wear on their crown tips offers further

302 information that the fossil leopard should have been younger than five years old at death.

303 A behavioral or sedimentary origin?

304 Extant leopards tend to carry their prey to a safe, isolated location for storage (de Ruiter \&

305 Berger, 2000). Many studies, based on field observation, indicated that the leopards in South

306 Africa prefer carrying their prey into their caves, thus contributing to the large number of skeletal

307 remains in many caves in South Africa (Le Roux \& Skinner, 1989). In addition to the fossil

308 leopard teeth, many mammalian fossils, such as deers (Cervus sp.), macaques (Macaca sp.), and

309 hystrixes (Hystrix sp.), were also uncovered from Longshia-dong Cave. These mammalian

310 fossils were once considered the kills brought back by leopards. Nevertheless, a previous study

311 pointed out that the deposit in Longshia-dong Cave is a result of multiple reworkings (Wang,

312 2015). The co-occurrence of the mammalian fossils in Longshia-dong Cave probably represents

313 a fossil accumulation over thousands of years.

314 Moreover, leopards left various bite marks on prey’s bones (Shi \& Wu, 2011; Binford, 315 2014), but Lin (2017) examined fossil bones from Longshia-dong Cave and failed to find any

316 common bite marks. Most deer fossils from the cave are mandibles or limb bones, all of which

317 are unfavorable to leopards ( $\mathrm{Li}, 2007)$. Thus, we suggest that the accumulation of mammalian

318 fossils in Longshia-dong Cave is very likely a result of multiple reworkings.

319 A comparison of the fossil teeth from Longshia-dong Cave to Chinese leopard fossils

320 Leopards are widely distributed throughout Asian and African continents, but only a few of

321 them are currently present on islands such as Java and Sri-Lanka (Pocock, 1932). No written

322 literature in Taiwan has reported the presence of leopards; however, this study reported the first 
323 leopard fossils from Longshia-dong Cave and thus suggested the presence of leopards in the Late 324 Pleistocene of Taiwan.

325 Many previous studies suggested a continental origin of Taiwanese mammalian fossils 326 based on various lines of evidence (Otsuka \& Lin, 1984; Lai, 1989; Qi et al., 1999; Chen, 2000a;

327 Fooden \& Wu, 2001). The Late Pleistocene of China has produced numerous leopard fossils 328 from various sites, including Beijing Mentougou Niuyan Cave (Deng et al., 1999), the first and 329 thirteenth locations of Beijing Zhoukoudian Site (Pei, 1934), Shaanxi Lantian Gongwangling 330 Site (Hu \& Qi, 1978), Anyang Yinxu Site (Teilhard de Chardin \& Young, 1936), and Guangxi 331 Liucheng Cave (Pei, 1987) (Fig. 10). Among these reports, Deng et al. (1999) claimed that the 332 two lower first molars of the three fossil leopard teeth uncovered from Mentougou Niuyan Cave 333 are the smallest $(19.3 \times 9.2 \mathrm{~mm}$ and $19.5 \times 8.5 \mathrm{~mm})$ in comparison with the other Chinese fossil 334 leopard teeth. The size of the fossil teeth in our study (16.77×7.95 mm; Tab. 3), however, are 335 much smaller than the teeth reported in Deng et al. (1999). The smaller dental size can be 336 explained by three hypotheses: (1) ontogenetic variation, (2) individual size variability, and (3) 337 insular dwarfism. The first hypothesis is here precluded as both of our specimen and the 338 Mentougou Niuyan Cave specimen are permanent teeth. The second hypothesis is currently a 339 working hypothesis in the presence of only one fossil specimen. Despite the uncertainty arisen 340 from the poor sample size $(\mathrm{N}=1)$, the third hypothesis is an interesting explanation. Meiri et al.

341 (2005) indicated that the $\mathrm{m} 1$ size in carnivores randomly varies in different habitats, albeit not 342 regularly and predictably with either area or isolation. They concluded three selective forces, 343 including resource limitation, predation, and interspecific competition. Our study area, Kenting

344 National Park, has produced less various fossils than all aforementioned Chinese sites, 345 suggesting a habitat with fewer resources for carnivores. Besides, the leopard described in this 
346 study is the only carnivores found in Kenting National Park to date, potentially indicating lower

347 predation pressure by other carnivores and the absence of interspecific competition. While the

348 absence of interspecific competition would have resulted in gigantism, both of the fewer

349 resources and lower predation pressure possibly contributed to the smaller size of Taiwanese

350 leopards than Chinese leopards. Yet, more specimens are required for further studies and will

351 help illuminate the smaller dental size of the Longshia-dong Cave specimen

\section{Conclusions}

354 Leopards are a group of carnivores widely distributed throughout Asian and African

continents, yet they are no longer found in eastern Asia due to civilization. Fossils thus represent

the only clue indicating prehistoric leopards. While their teeth are significantly smaller than the

other leopard teeth compared and thus are easily identified, poorly preserved fossils hinder

358

further investigations. This study, based on an integration of morphological and geometric

morphometric analyses, reveals the assignment of the fossil teeth excavated from Longshia-dong

360 Cave to Panthera pardus, which is currently absent on Taiwan Island and suggests the presence

of leopards in the Late Pleistocene of Taiwan. Such a record of prehistoric leopards in Taiwan

362 thus adds up to the carnivore biodiversity of Taiwan. However, whether the Panthera individual

363 is aboriginal or migrated is still uncertain. Our study also found that the teeth from Longshia-

364 dong Cave belonged to a smaller individual in comparison with the fossil record from China

365 indicates the smaller size of Taiwanese leopard fossil teeth than Chinese ones. Such a smaller

366 dental size was possibly a result of individual size variability or insular dwarfism. To conclude,

367 the discovery of the leopard fossil in Taiwan opens shed some light on the origin of the Kenting 
368 Fauna. Nevertheless, the insular dwarfism of, and the migration history of, the prehistoric 369 leopards in Taiwan are still speculations and thus require more specimens and studies.

370

371 Acknowledgements

372

The authors would like to thank Y.- J. Chen of NMNS, S.-W. Chang of the Endemic

373 Species Research Institute, and T.-C. Chan of Taipei Zoo for their assistance in accessing the

374 specimens. We are also grateful to P.-J. Chiang for his helpful comments and J. Chen for her 375 help on illustrations. Two anonymous reviewers and Martin Sabol have helped improve this 376 study with their constrictive comments. Appreciation also goes to all members of the Taiwan377 Japan joint excursion in 2014. We also thank K.-C. Wang and T.-Y. Hsiao for their assistance in 378 the excursion. We also thank J.-S. Chi for proofreading. This study was supported by the grants 379 of the Ministry of Science and Technology (MOST), Taiwan (102-2116-M-178-004- to C.-H. 380 Chang and 108-2116-M-178-003-MY2 and 110-2116-M-178-002 to T.-R. Yang).

\section{References}

383 Asahara M, Chang C-H, Kimura J, Son NT, and Takai M. 2015. Re-examination of the fossil raccoon dog (Nyctereutes procyonoides) from the Penghu channel, Taiwan, and an age estimation of the Penghu fauna. Anthropological Science 123:177-184. doi:10.1537/ase. 150710

Binford LR. 2014. Bones: Ancient Men and Modern Myths. Academic press, New York. 320 p. Chen K-T. 2000a. On Taiwan mammalian faunas in different periods of time and related problems: The background materials for Taiwan zooarchaeological studies, part 1. 
Bulletin of the Institute of History and Philology Academia Sinica 71:129-198. doi:

391 10.6355/BIHPAS.200003.0129

392 Chen K-T. 2000b. On Taiwan mammalian faunas in different periods of time and related

393

394

395

396

397

398

399

400

401

402

403

404

405

406

407

408

409

410

411

412

problems: The background materials for Taiwan zooarchaeological studies, part 2.

Bulletin of the Institute of History and Philology Academia Sinica 71:367-457. doi: 10.6355/BIHPAS.200006.0367

Chen W-S, Lee W-C, Huang N-W, Yen I-C, Yang C-C, Yang H-C, Chen Y-C, and Sung S-H. 2005. Characteristics of accretionary prism of Hengchun Peninsula, southern Taiwan: Holocene activity of the Hengchun fault. Western Pacific Earth Sciences 5:129-154. (in Chinese with English abstract)

Chi W-R. 1982. The calcareous nannofossils of the Lichi Melange and the Kenting Melange and their significance in the interpretation of plate-tectonics of the Taiwan region. $\mathrm{Ti}$-Chih (Geology) 4:99-114. (in Chinese with English abstract)

Chiang P-J, Pei KJ-C, Vaughan MR, Li C-F, Chen M-T, Liu J-N, Lin C-Y, Lin L-K, and Lai YC. 2015. Is the clouded leopard Neofelis nebulosa extinct in Taiwan, and could it be reintroduced? An assessment of prey and habitat. Oryx 49:261-269. doi: $10.1017 / \mathrm{S} 003060531300063 \mathrm{X}$

Choe RS, Han KS, Kim SC, U C, Ho CU, and Kang I. 2020. Late Pleistocene fauna from Chongphadae Cave, Hwangju County, Democratic People's Republic of Korea. Quaternary Research 97:42-54. doi: doi.org/10.1017/qua.2020.9

Christiansen P. 2008. Species distinction and evolutionary differences in the clouded leopard (Neofelis nebulosa) and Diard's clouded leopard (Neofelis diardi). Journal of Mammalogy 89:1435-1446. doi:10.1644/08-MAMM-A-013.1

Peer) reviewing PDF | (2020:08:51992:2:0:NEW 25 Jul 2021) 
413 Christiansen P, and Kitchener AC. 2011. A neotype of the clouded leopard (Neofelis nebulosa 414 Griffith 1821). Mammalian Biology 76:325-331. doi:10.1016/j.mambio.2010.05.002

415 de Ruiter DJ, and Berger LR. 2000. Leopards as taphonomic agents in dolomitic caves416 implications for bone accumulations in the hominid-bearing deposits of South Africa. 417 Journal of Archaeological Science 27:665-684. doi:10.1006/jasc.1999.0470

418 Deng T Huang W, and Wang H. 1999. The Late Pleistocene mammalian fossils from Niuyan 419 Cave in Mentougou, Beijing, China. Vertebrata Palasiatica 37:156-164.

420 Dunteman GH. 1994. Principal Component Analysis (PCA). Sage Publications, Newbury Park. 421 $96 \mathrm{p}$.

422 Fischer von Waldheim G. 1817. Adversaria zoologica. Mémoires de la Société Imperiale des 423 Naturalistes de Moscou 5:368-428.

424

Fooden J, and Wu H-Y. 2001. Systematic review of the Taiwanese Macaque, Macaca cyclopis Swinhoe, 1863. Fieldiana Zoology 98: 1-70.

Fukawa M. 2000. Research Methods for Fossils. Kyoritsu Shuppan, Tokyo. 388 p.(in Japanese)

427

428

429

430

431

432 433 434 435
Gan Y. 2016. Study the Late Pleistocene cat (Carnivora, Felidae) fossils from a limestone cave within Kenting Area, southern Taiwan. Master Thesis. Department of Earth Sciences, National Cheng Kung University Tainan. 107 p.

Gong S-Y. 1982. Study stratigraphic and paleoenvironmental of Hengchun Limestone. Master Thesis. Department of Geology, National Taiwan University, Taipei. 60 p.

Gong S-Y. 1994. Pleistocene carbonate deposition in the Kueitzechiao-Oluanpi area, Hengchun, Taiwan: A preliminary study. Journal of Geological Society of China 37:165-188

Gong S-Y, and Yui T-F. 1998. Meteoric diagenesis and stable isotopic compositions of the Hengchun Limestone, southern Taiwan. Journal of Geological Society of China 41:1-24. 
436 Gould GC. 2001. The phylogenetic resolving power of discrete dental morphology among extant

437

438

439

440

441

442

443

444

445

446

447

448

449

450

451

452

453

454

455

456

457

458

hedgehogs and the implications for their fossil record. American Museum Novitates

3340:1-52. doi:10.1206/0003-0082(2001)340<0001:TPRPOD>2.0.CO;2

Gray JE. 1867. Notes on the skulls of the cats (Felidae). Proceedings of the Zoological Society of London 1867:258-277. doi:10.1111/j.1469-7998.1867.tb00432.x

Gunz P, and Mitteroecker P. 2013. Semilandmarks: a method for quantifying curves and surfaces. Hystrix 24:103-109. doi:10.4404/hystrix-24.1-6292

Hemmer H. 1966. Untersuchungen zur Stammesgeschichte der Pantherkatzen (Pantherinae). Teil I. Veröffentlichungen der Zoologischen Staatssammlung München 11:1-121. (in German) Hillson S. 2005. Teeth: Cambridge University Press, Cambridge. 373 p.

Ho C-K, Qi G-Q, and Chang C-H. 1997. A preliminary study of Late Pleistocene Carnivore fossils from the Penghu Channel, Taiwan. Journal of the National Taiwan Museum 40:195-224. doi:10.6548/ATMB.199712_40.0007

Hseu Z-Y, Wang H-H, Wu S-H, and Chang I-S. 2004. Pedogenesis and classification of soils in the Kenting uplifted coral reef nature reserve, Southern Taiwan. Taiwan Journal of Forest Science 19:153-164.

Hsu C-C. 2003. Geomorphometric study of Octopus and Cistopus (Cephalopoda: Octopodidae) based on landmarks of beaks. Master Thesis. National Sun Yat-sen University. 66 p.

Hsu M-Y. 1989. A geomorphological study of marine terraces in Taiwan. PhD Thesis. Department of Geography, Chinese Culture University, Taipei. 178 p.

Hu C, and Qi T.. 1978. Gongwangling Pleistocene mammalian fauna of Lantian, Shaanxi. Palaeontologica Sinica ser. C 21:1-64. (in Chinese with English abstract) 
459 Huang C-Y, Cheng Y, and Jeh C. 1985. Genesis of the Kenting Formation in the Hengchun 460 Peninsula, southern Taiwan. Ti-Chih (Geology) 6:21-38. (in Chinese with English $461 \quad$ abstract)

462 Jin C, Zheng J, Wang Y, Xu Q. 2008. The stratigraphic distribution and zoogeography of the 463 early pleistocene mammalian fauna from south China. Acta Anthropologica Sinica $464 \quad$ 27:304-317. (in Chinese with English abstract)

465 Jolliffe IT. 2002. Principal Component Analysis. Springer series in statistics 29. 488 p.

466 Kawamura A, Chang C-H, and Kawamura Y. 2016. Middle Pleistocene to Holocene mammal 467 faunas of the Ryukyu Islands and Taiwan: An updated review incorporating results of recent research. Quaternary international 397:117-135. doi:10.1016/j.quaint.2015.06.044

469

470

471

472

473

474

475

476

477

478

479

480

481

482

Kawamura Y. 1992. Collecting technique and storage system for micro-mammalian fossils. Honyurui Kagaku (Mammalian Science) 31:99-104.

King LM. 2012. Phylogeny of Panthera, including P. atrox, based on cranialmandibular characters. Master Thesis. East Tennessee State University, Johnson City. 160 p.

Lai K-Y. 1989. The fossil record of mammals in Taiwan. Monograph of the Symposium on the Geographical Origin of the Fauna of Taiwan. Taipei. p 26-49.

Le Roux P, and Skinner J. 1989. A note on the ecology of the leopard (Panthera pardus Linnaeus) in the Londolozi Game Reserve, South Africa. African Journal of Ecology 27:167-171. doi:10.1111/j.1365-2028.1989.tb00940.xLi Q. 2007. Fauna analysis of Zhoukoudian Tianyuan Cave human fossil site. Master Thesis. Institute of Vertebrate Paleontology and Paleoanthropology, Chinese Academy of Sciences, Beijing. 66 p.

Li X, and Deng K. 2003. Early Pleistocene carnivore fossils from Zhen'an, Shaanxi, China. Journal of Northwest University (Natural Science Edition) 33:455-459. (in Chinese with English abstract) 
483 Li Y, Pei S, Tong H, Yang X, Cai Y, Liu W, and Wu X. 2013. A preliminary report on the 2011

484 excavation at Houbeishan Fuyan Cave, Daoxian, Hunan Province. Acta Anthropologica

$485 \quad$ Sinica 32:133-143. (in Chinese with English abstract)

486 Lin C-Y. 2017. Study on fossil deer in a limestone cave from the Late Pleistocene of Kenting

487 area, southern Taiwan. Master Thesis. Department of Life Sciences, Tunghai University, $488 \quad$ Taichung. 224 p.

489 Linnaeus C. 1758. Systema naturae: Stockholm Laurentii Salvii.

490 Meachen-Samuels J, and Van Valkenburgh B. 2009. Craniodental indicators of prey size 491 preference in the Felidae. Biological Journal of the Linnean Society 96:784-799. 492 doi:10.1111/j.1095-8312.2008.01169.x

493 Meiri S, Dayan T, and Simberloff D. 2005. Area, isolation and body size evolution in insular $494 \quad$ carnivores. Ecology Letters 8:1211-1217. doi:10.1111/j.1461-0248.2005.00825.x 495 Morrison D. 1976. The structure of multivariate observations: I. Principal components. 496 Multivariate Statistical Methods 2:266-301.

497 Oken, L. 1816. Okens Lehrbuch der Naturgeschichte. Dritter Theil. Zoologie. Mit viezig 498 Kupfertafeln. Zweite Abtheilung. Fleischthiere. August Schmid und Comp., Jena. 1270 p.

499 Otsuka H. 1984. Stratigraphic position of the Chochen vertebrate fauna of the Toukoushan 500 Group in the environs of the Chochen District, Southwest Taiwan, with special reference $501 \quad$ to its geologic age. Quarterly Journal of the Taiwan Museum 37:37-55.

502 doi:10.6532/JTM.198406_37(1).0002

503 Otsuka H, and Lin C-C. 1984. Fossil rhinoceros from the Toukoushan Group in Taiwan. Journal $504 \quad$ of Taiwan Museum 37:1-35.

505 Pei W. 1934. On the Carnivora from locality 1 of Choukoutien. Paleontologia Sinica ser. C 506 8:76-80. (in Chinese with English abstract) 
507 Pei W. 1987. Carnivora, Proboscidea and Rodentia from Liucheng Gigantopithecus cave and $508 \quad$ other caves in Guangxi. Memoirs of Institute of Vertebrate Paleontology and 509 Paleoanthropology, Academia Sinica 18:5-134.

510 Pocock R. 1917. XL.- The classification of existing Felidae. Journal of Natural History. p 329511 350. doi:10.1080/00222931709487018

512 Pocock R. 1930. The panthers and ounces of Asia. Volume II. Journal of Bombay Natural 513 History Society 34: 329-336.

514 Pocock R. 1932. The leopards of Africa. Proceedings of the Zoological Society of London

515 26:543-591. doi:10.1111/j.1096-3642.1932.tb01085.x

516 Qi G-Q, Ho C-K, and Chang C-H. 1999. The Pleistocene fossil suids from Chochen, Tainan, 517 southwestern Taiwan. Collection and Research 12:33-40.

518 R Core Team. 2013. A language and environment for statistical computing. R Foundation for $519 \quad$ Statistical Computing. Vienna, Austria.

520

521

522

523

524

525

526

527

528

529

530

Rohlf FJ. 2005. tpsDig, digitize landmarks and outlines, version 2.05. Department of Ecology and Evolution, State University of New York at Stony Brook.

Rohlf FJ. 2007. tpsRelw version 1.45. Department of Ecology and Evolution, State University of New York, Stony Brook.

Shi M, and Wu X. 2011. The microscratch trace of animal bone surface and human behavior study of Kua Hu Qiao Site in Xiaoshan District, Zhejiang Province. Quaternary Sciences 31:723-729.

Shih T-T, Tsai W-T, Hsu M-Y, Mezaki S, and Koba M. 1989. The study of ages and terraces of coral reef in the Kenting National Park Area. Conservation Research Report of the Kenting National Park Headquarters, Construction and Planning Agency, Ministry of the Interior. $58 \mathrm{p}$. 
531 Slice DE. 1996. Introduction to landmark methods. in (eds.) Marcus LF, Corti M, Loy A, Naylor

532 GJP, Slice DE. Advances in Morphometrics: Springer, Boston. pp. 113-115.

533 doi:10.1007/978-1-4757-9083-2_10

534 Stander P. 1997. Field age determination of leopards by tooth wear. African Journal of Ecology

$535 \quad 35: 156-161$. doi:10.1111/j.1365-2028.1997.068-89068.x

536 Suzuki H. 1966. Skeletal remains of Hamakita Man. Journal of the Anthropological Society of Nippon 74:172-174. (In Japanese)

538 Swinhoe R. 1862. On the Mammals of the island of Formosa (China). Proceedings of the 539 Zoological Society of London 30:347-368. doi:10.1111/j.1469-7998.1862.tb06539.x

540 Swinhoe R. 1870. Catalogue of the mammals of China (south of the Yangtsze) and of the island 541 of Formosa. Proceedings of Zoological Society of London 22:615-653.

542 Teilhard de Chardin PT, and Pei W. 1941. The fossil mammals from Locality 13 of 543 Choukoutien. Palaeontologica Sinica ser. C 11:1-106.

544 Teilhard de Chardin PT, and Young C. 1936. On the mammalian remains from the 545 archaeological Site of Anyang. Palaeontologica Sinica ser. C 12:1-78.Todd NE. 2010. New phylogenetic analysis of the family Elephantidae based on cranial-dental morphology. Anatomical Record (Hoboken) 293:74-90. doi:10.1002/ar.21010

548 Tseng JZ, Wen H, and Chen S-Q. 2010. Geometric morphometrcs analysis of cranial shape 549 550 among late Miocene hyaenid ecomorphologies in the Linxia Basin, Gansu, China. Vertebrata Palasiatica 48:235-246.

Van Cleef-Roders JT, and van den Hoek Ostende LW. 2001. Dental morphology of Talpa 552 europaea and Talpa occidentalis (Mammalia: Insectivora) with a discussion of fossil 553 Talpa in the Pleistocene of Europe. Zoologische Mededelingen 75:51-68. 
554 Wang J, Chen J, Chen Q, and Lu T. 1990. The discovery and exploitation of the resources of

555

556

557

558

559

560

561

562

563

564

565

566

567

568

569

570

571

572

573

574

575

576 animal fossils in Panlongdong Cave, Yunfu County, Guangdong Province. Tropical Geography 10:333-339. (in Chinese with English abstract)

Wang K-C. 2015. Rodent fossils from late Quaternary limestone cave in Kenting area, southern Taiwan. Master Thesis. Department of Earth Sciences, National Cheng Kung University, Tainan. $174 \mathrm{p}$.

Wang L, Lin Y, Chang S, and Yuan J. 1982. Mammalian fossils found in northwest part of Huan Province and their significance. Vertebrata Palasiatica 4:350-358. (in Chinese with English abstract)

Wei K-Y. 2007. Quaternary mammalian fossils of Taiwan: an eclectic overview and prospects for future study. in (ed.) Wei K-Y. Studies on the Quaternary Geology of Taiwan: Overview and Prospect. Special Publication of the Central Geological Survey 18:261286.

Wu X, Deng X, and Zheng L. 2008. Late Pleistocene fauna at Yang'er Cave in Hunan Province. Quaternary Sciences 28: 1114-1128. (in Chinese with English abstract)

Wu X, Pei S, Wu X, Qu S, Chen M, Hu Q, and Liu W. 2009. A preliminary study of the Bailong Cave paleoanthropological site in Yunxi County, Hubei Province. Acta Anthropologica Sinica 28:1-15. (in Chinese with English abstract)

Xu C, Zhang Y, Chen C, and Fang D. 1984. Human occipital bone and mammalian fossils from Chaoxian, Anhui. Acta Anthropologica Sinica 3:202-301. (in Chinese with English abstract)

Yen T-P, and Wu C-Y. 1986. The Pliocene and younger formations in the southern part of the Hengchun Peninsula. Ti-Chih (Geology) 7:1-10. (in Chinese with English abstract) 
577 You Y, and Qi G. 1973. New materials of Pleistocene mammals in Yuanmou, Yunnan.

$578 \quad$ Vertebrata Palasiatica 11:66-80. (in Chinese with English abstract)

579 Young C. 1935. Note on a mammalian microfauna from Yenchingkou near Wanhsien, Szechuan.

$580 \quad$ Bulletin of the Geological Society of China 14:247-248. (in Chinese with English

581 abstract)Zelditch ML, Fink WL, and Swiderski DL. 1995. Morphometrics, homology,

582 and phylogenetics: quantified characters as synapomorphies. Systematic Biology 44:179-

583 189. doi: $10.2307 / 2413705$

584

Zelditch ML, Lundrigan BL, and Garland Jr T. 2004. Developmental regulation of skull

585 morphology. I. Ontogenetic dynamics of variance. Evolution \& Development 6:194-206.

586 doi:10.1111/j.1525-142X.2004.04025.X

587 Zhang Y, Long Y, Ji H, and Ding S. 1989. The Cenozoic deposits of the Yunnan region.

588 Professional Papers on Stratigraphy and Paleontology 7:1-21. (in Chinese)

589 Zhao L, Zhang L, Xu C, Wang X, and Cai H. 2013. New discovered Early Pleistocene mammal 590 fossils and bone artifact in Hezhang of Guizhou Plateau. Acta Anthropologica Sinica 32:477-484. (in Chinese with English abstract)

592 Zhao L, Zhang L, Du B, Nian X, Zheng Y, Zhang Z, Wang C, Wang X, and Cai H. 2016. New 593 discovery of human fossils and associated mammal fauna from Mawokou Cave in Bijie, 594 Guizhou Province of southern China. Acta Anthropologica Sinica 35:24-35. (in Chinese $595 \quad$ with English abstract)

596 
Figure 1

Location and geological map of the discovery site of the leopard fossils in Taiwan

A map of Taiwan shows the location of the Kenting National Park (a), and a geological map of southernmost Taiwan is presented in (b). The location of the discovery site, Longshia-dong Cave, is indicated by a red star in (b).

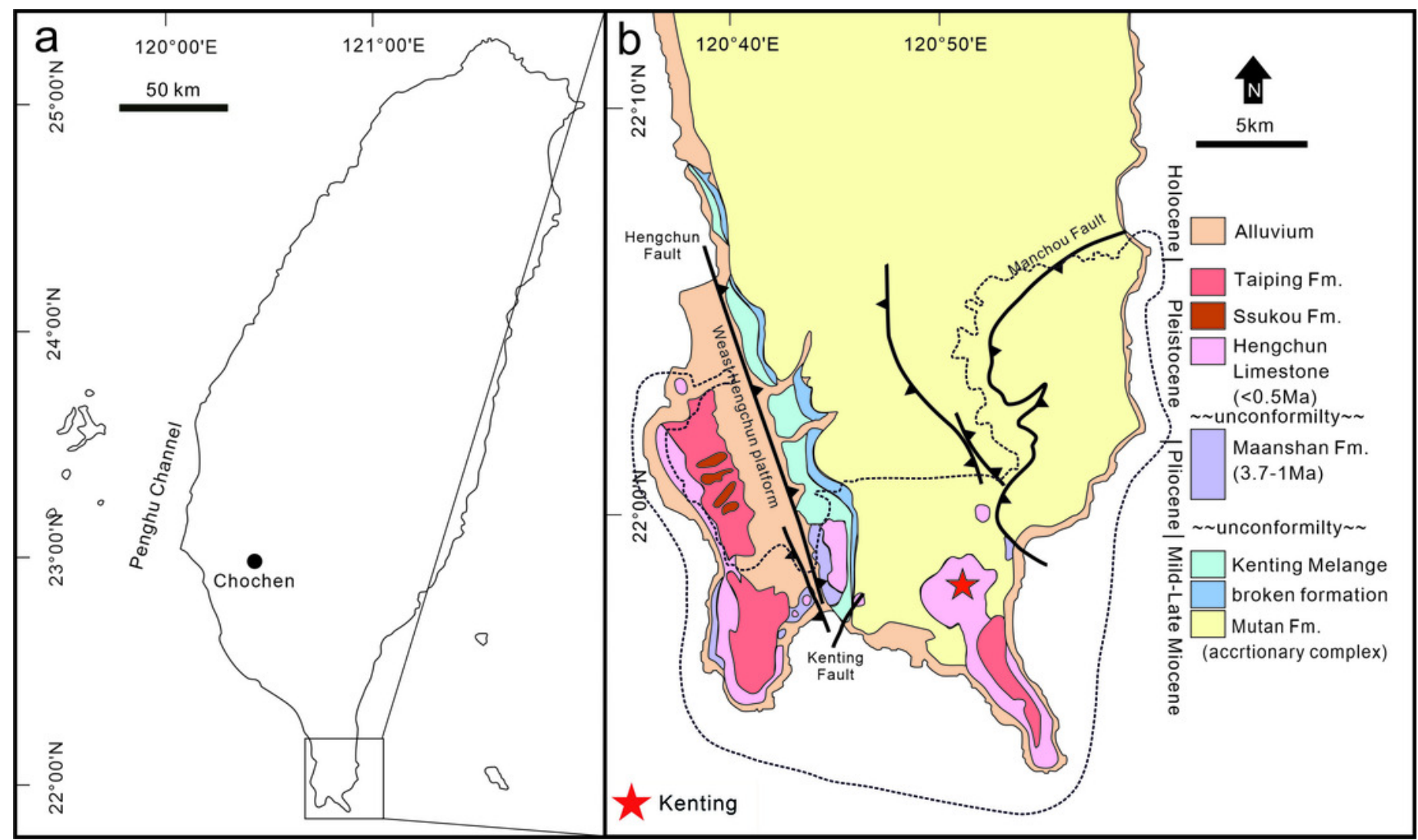




\section{Figure 2}

The three felid lower cheek teeth from Longshia-dong Cave

The three felid lower cheek teeth from Longshia-dong Cave, including p3 (a, F056584), p4 (b, F056585), and m1 (c, F056585), and their buccal views (1), lingual views (2), and occlusal views (3).

$a^{1}$

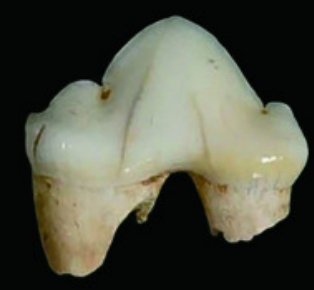

$a^{2}$

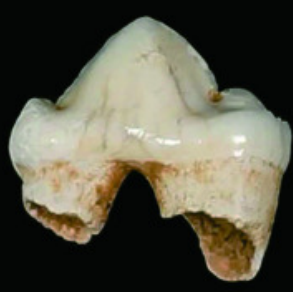

$a^{3}$

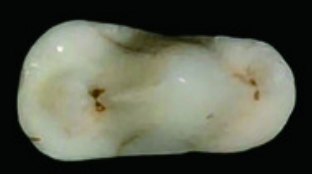

$1 \mathrm{~cm}$ $b^{1}$

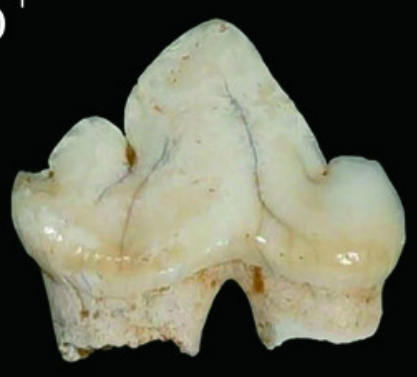

$b^{2}$

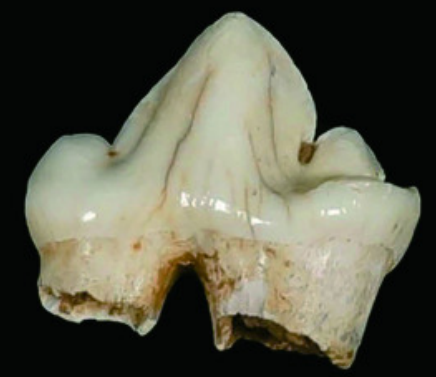

$b^{3}$

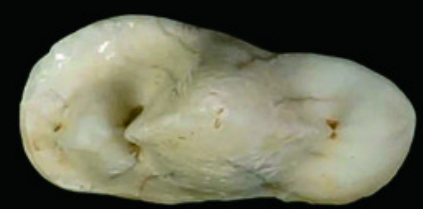

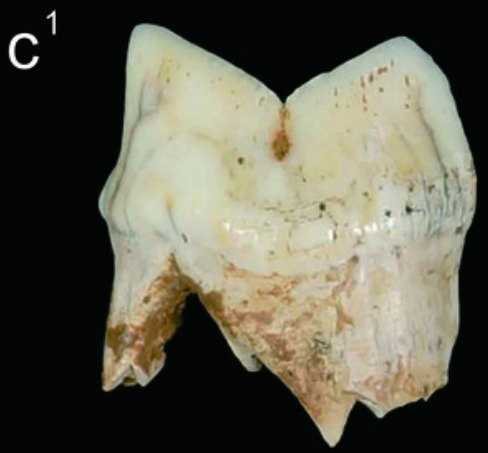

$c^{2}$

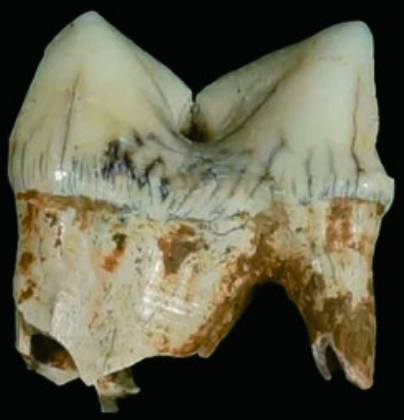

$c^{3}$

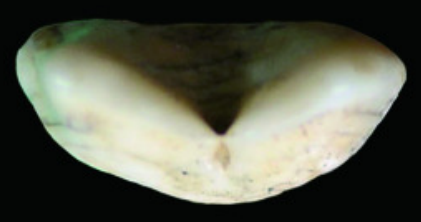




\section{Figure 3}

A comparison of the teeth ( $p 3, p 4$, and $m 1)$ of three pantherines

A comparison of the teeth ( $p 3, p 4$, and $\mathrm{m} 1$ ) of three pantherines including (a) clouded leopard, (b) leopard, and (c) tiger. Three significant characters are indicated by (1) the developmental level of $p 3$ paraconid, (2) the shape of $p 4$ occlusal surface (the difference between paraconid and protoconid widths), and (3) the size difference between $\mathrm{ml}$ paraconid and $\mathrm{m} 1$ protoconid. 
p3 $\quad \mathrm{p} 4 \quad \mathrm{~m} 1$
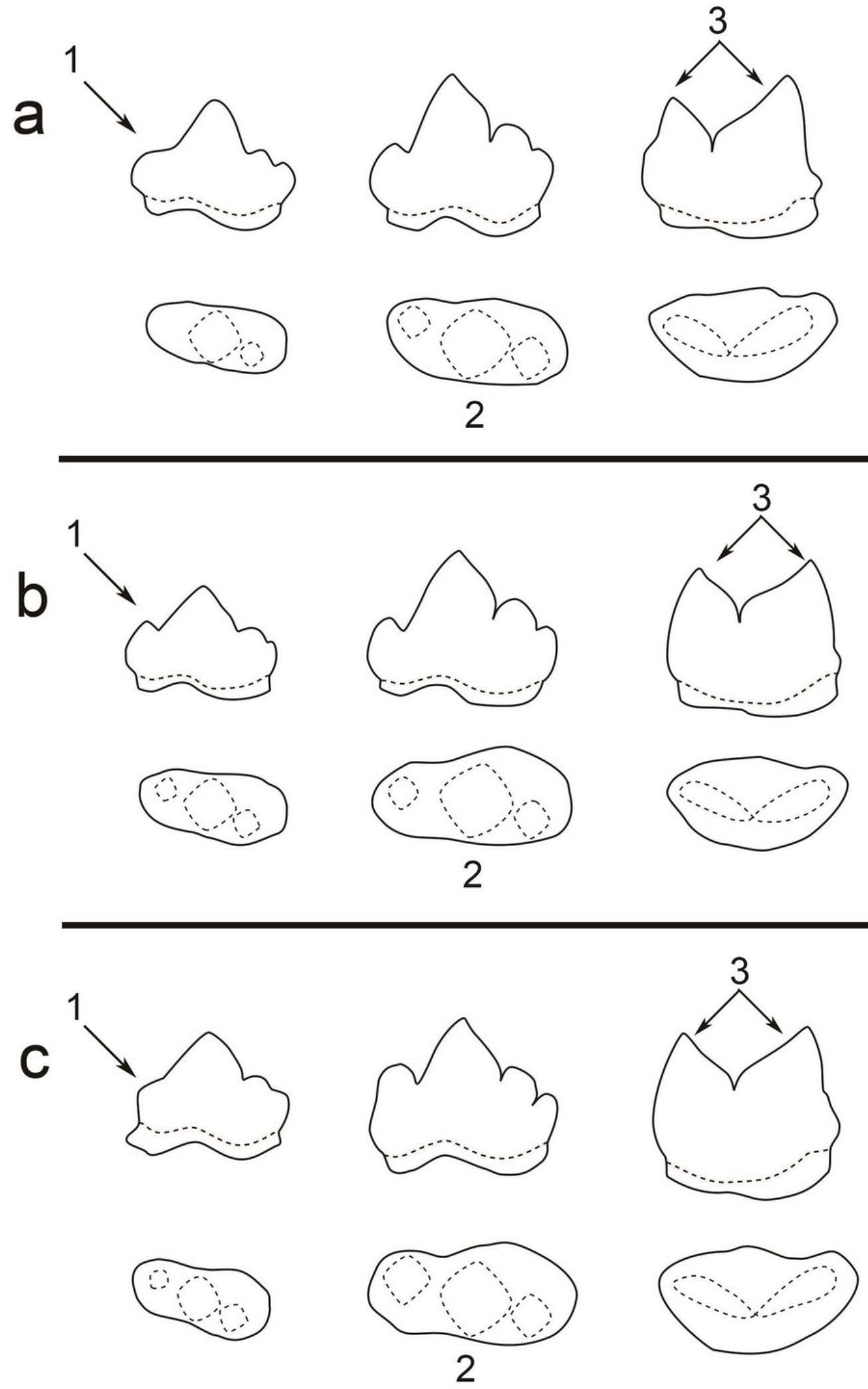
Figure 4

Measurements of $\mathrm{p} 3, \mathrm{p} 4$, and $\mathrm{m} 1$

Measurements of $\mathrm{p} 3, \mathrm{p} 4$, and $\mathrm{m} 1$ from the buccal side (a, from left to right) and from the occlusal side ( $b$, from left to right). For the numbered dimensions, see Tab. 1.
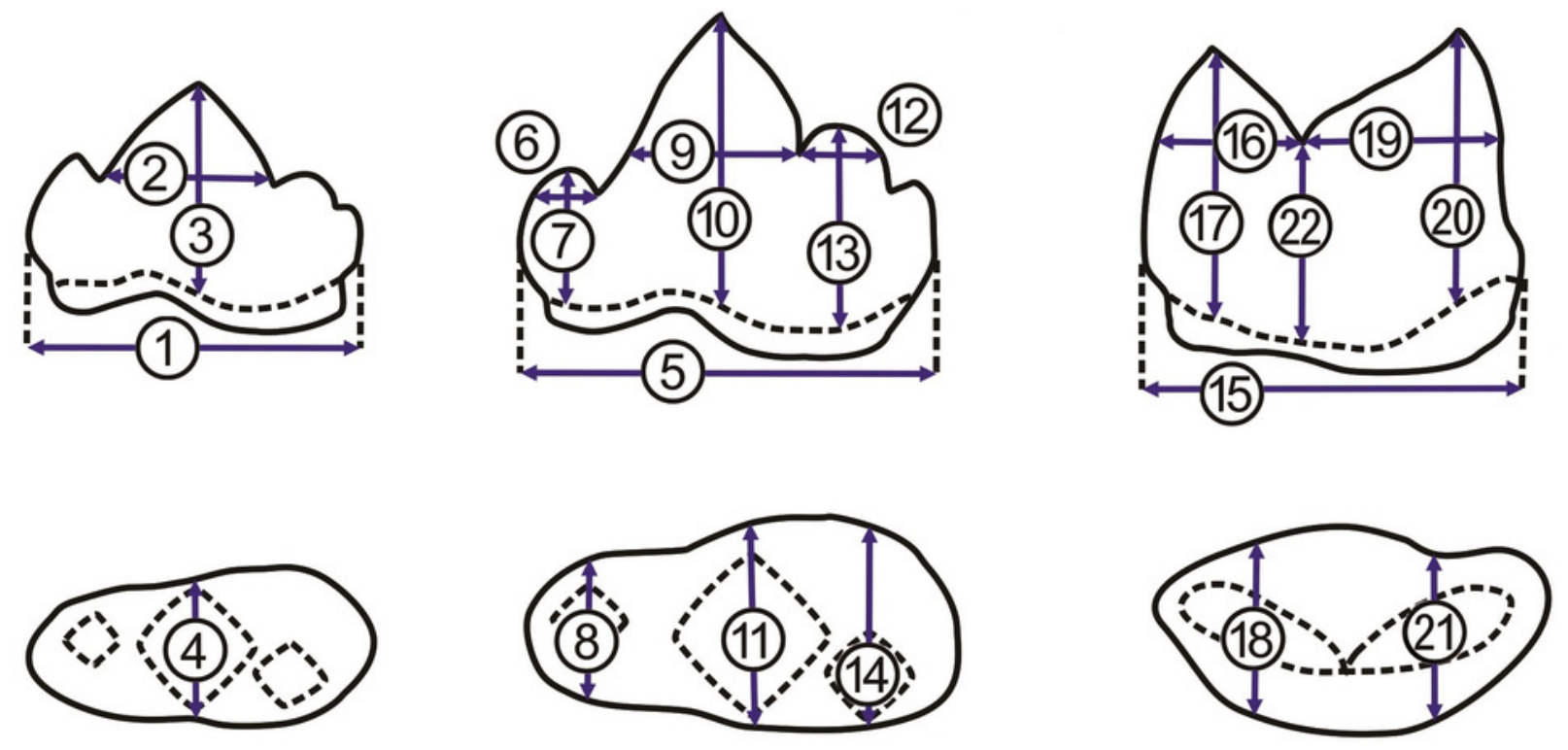


\section{Figure 5}

Two rounds of PCA analysis of the traditional linear measurements

The first round of PCA analysis based on all datasets is presented in (a). The second round of PCA analysis was performed for $\mathrm{p3}$ (b), p4 (c), and $\mathrm{m} 1$ (d), separately. The result from the three ratios converted from four $\mathrm{p} 3$ numbered dimensions ( $A: 2 / 1, B: 3 / 1, C: 2 / 3)$ is shown in (b). The result from the six ratios converted from seven $p 4$ numbered dimensions (A: 6/ 5, B: $7 / 5$, C: $9 / 5, \mathrm{D}: 10 / 5, \mathrm{E}: 12 / 5, \mathrm{~F}: 13 / 5$ is presented in (c). The result from the seven ratios converted from eight $\mathrm{m} 1$ numbered dimensions (A: 16/15, B: 17/15, C: 19/15, D: 20/15, E: 16/19, F: 17/20, G: 22/15 is shown in (d). See the details of the numbered dimensions in Fig. 3 and Tab. 1. Red triangles, Panthera tigris; yellow circles, Panthera pardus; cyan square, Neofelis nebulosa and Neofelis diardi; black cross, the studied fossil felid teeth. Red arrow represents a simplified ratio that shows the trend relating to the two principal components. Factor loadings of each principal component is indicated by the arrow length. 

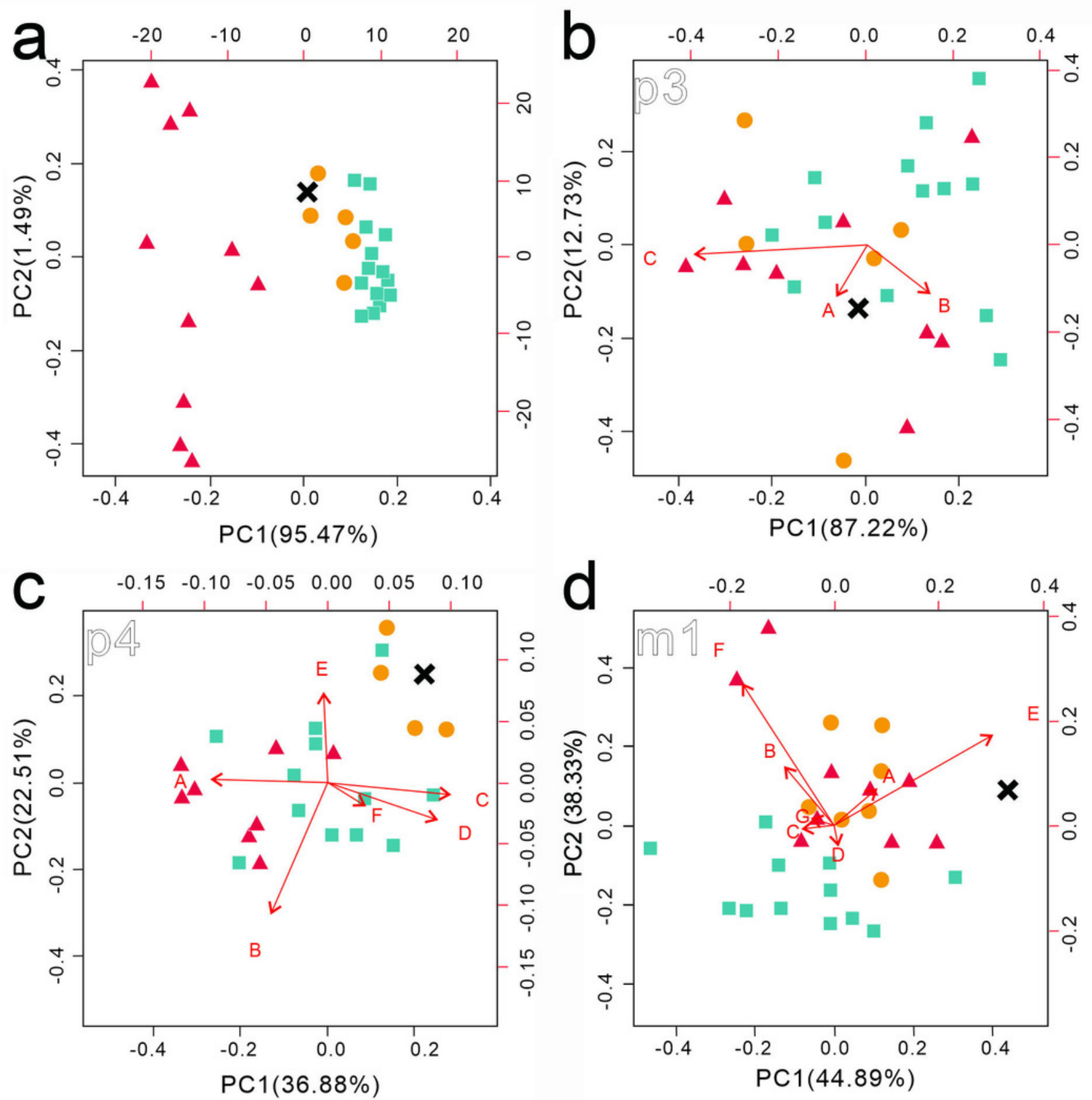

X Kenting fossil $\backsim$ clouded leopards $\bullet$ leopards $\Delta$ tigers 


\section{Figure 6}

A bivariate plot of selected numbered dimensions of $\mathrm{p} 3, \mathrm{p} 4, \mathrm{~m} 1$ of the fossil and extant leopard specimens

A bivariate plot of selected numbered dimensions $(1,4,5,11,15,21$ from Tab. 1) of p3, p4, $\mathrm{ml}$ of the fossil and extant leopard specimens (in $\mathrm{mm}$ ). Dotted light blue, black, dark blue, green, and purple lines represent the regression lines for the dimensions of the five extant specimens, including the right and left sides of the specimen no. 1348-1, the right and left sides of the specimen no. 1431-1, and the left side of the specimen no. 549-1 (see Supplemental Tab. 1). The regression line for the dimensions of the fossil specimen is marked in red. Triangles, p3; squares, p4; circles, m1. 


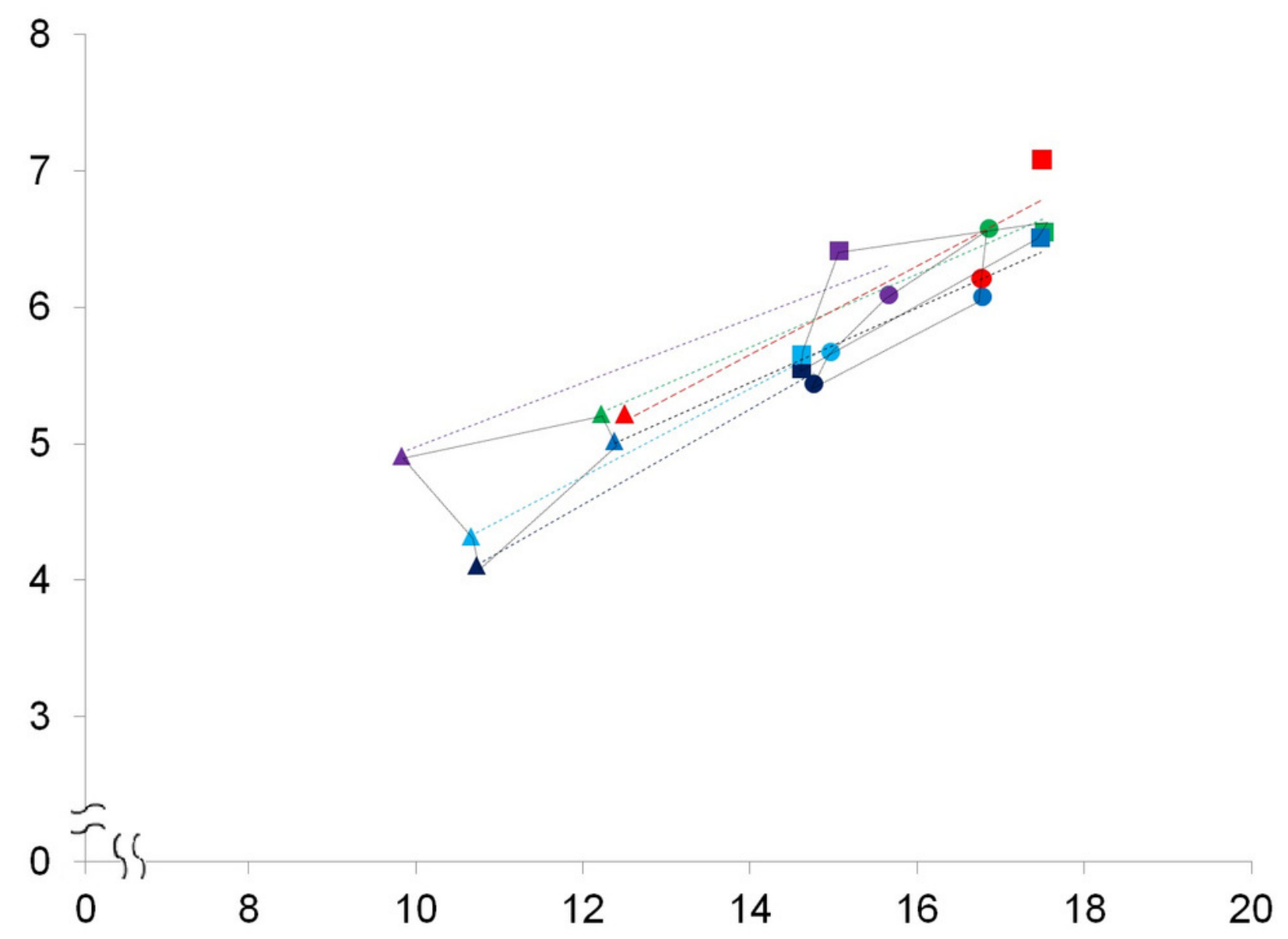




\section{Figure 7}

The shape variation of the occlusal surface of $p 3$ in three pantherines

The shape variation of the occlusal surface of $\mathrm{p} 3$ in three pantherines, as revealed by a principal components analysis of three warp scores. (a) RW1 versus RW2; (b) RW1 versus RW3; (c) RW2 versus RW3. RW1 in a positive direction explains $50.54 \%$ variance, RW2 in a positive direction explains $15.02 \%$ variance, and RW3 in a positive direction explains $9.25 \%$ variance. Red triangles, Panthera tigris; yellow circles, Panthera pardus; cyan square, Neofelis nebulosa and Neofelis diardi ; black cross, the studied fossil felid teeth.
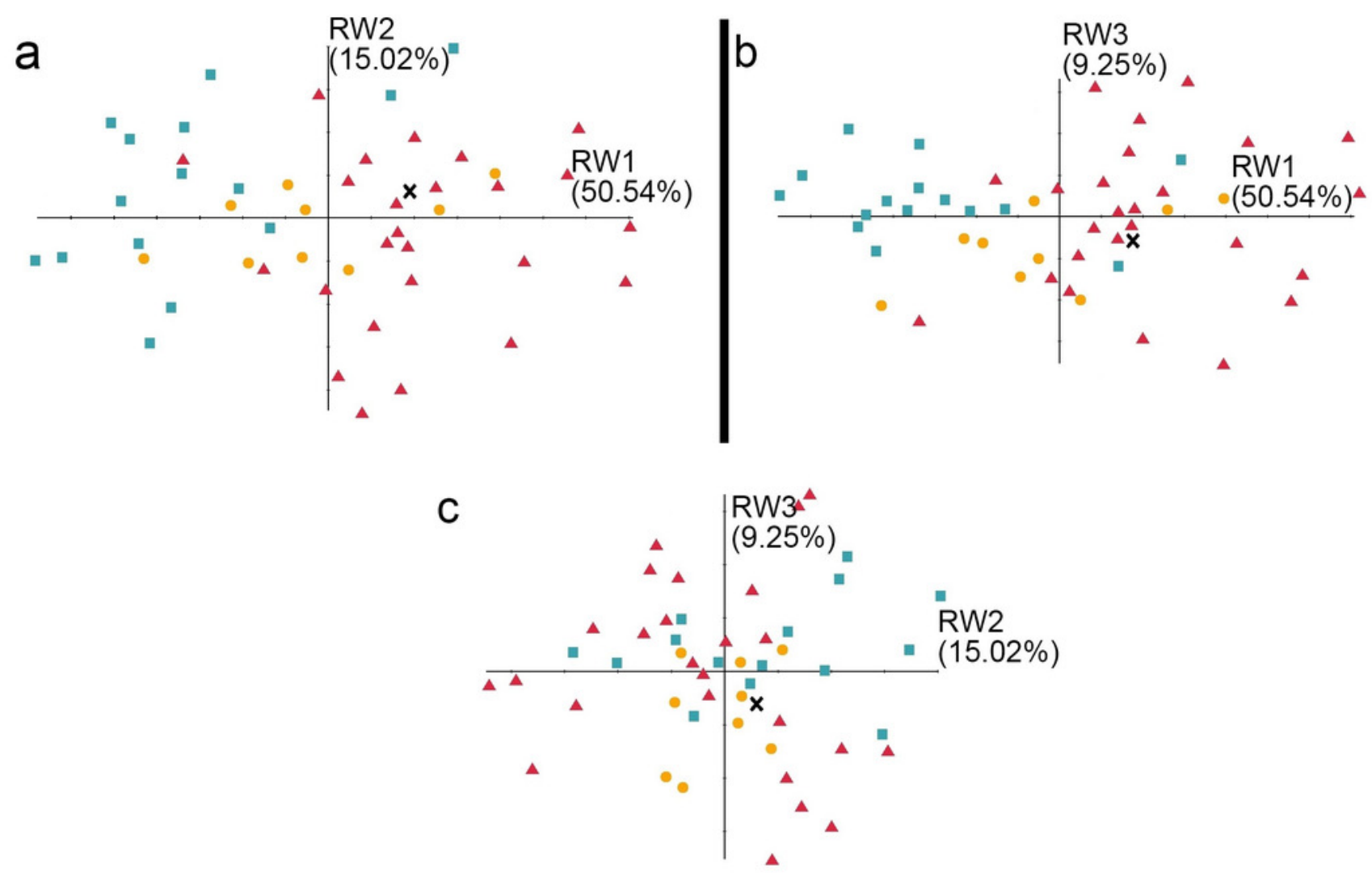


\section{Figure 8}

The shape variation of occlusal surface of p4 in three pantherines

The shape variation of occlusal surface of $\mathrm{p} 4$ in three pantherines, as revealed by a principal components analysis of warp scores. Plot of (a)RW1 versus RW2; (b) RW1 versus RW3; (c) RW2 versus RW3. Red triangles, Panthera tigris; yellow circles, Panthera pardus; cyan square, Neofelis nebulosa and Neofelis diardi; black cross, the studied fossil felid teeth. (d) the shape of fossil p4, (e) thin-plate spline deformation grid depicting shape variation along RW1 in a positive direction explains $46.01 \%$ variance, (f) thin-plate spline deformation grid depicting shape variation along RW2 in a positive direction explains $24.52 \%$ variance, (g) thin-plate spline deformation grid depicting shape variation along RW3 in a positive direction explains $9.05 \%$ variance.

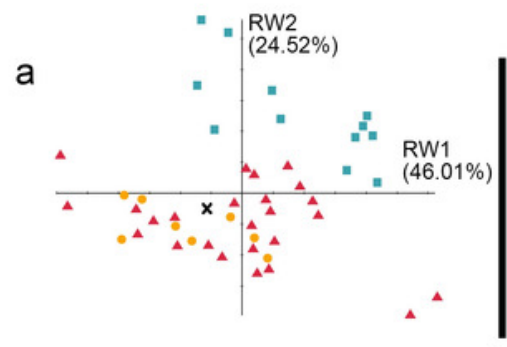

d

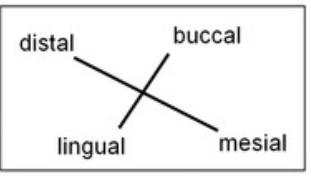

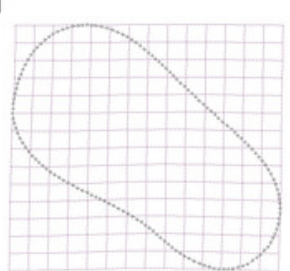

Fossil p4

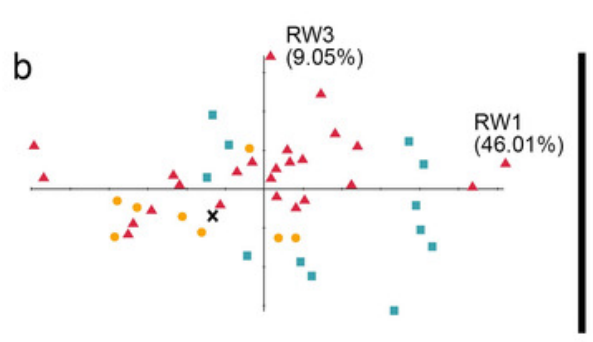

f

e

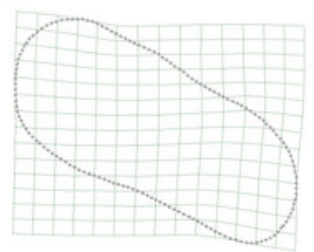

RW1

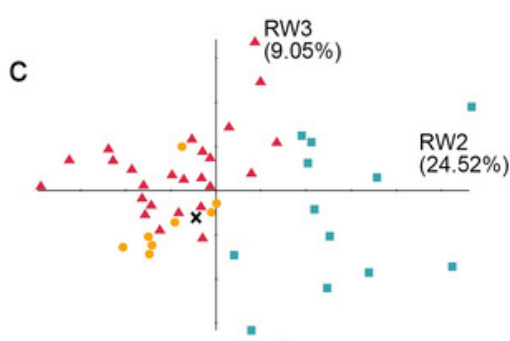

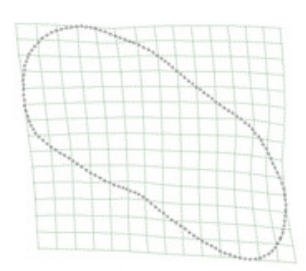

RW2 g

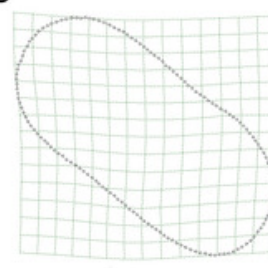

RW3 


\section{Figure 9}

The shape variation of occlusal surface of $\mathrm{m} 1$ in three pantherines

The shape variation of occlusal surface of $\mathrm{m} 1$ in three pantherines, as revealed by a principal components analysis of warp scores. (a) RW1 versus RW2; (b) RW1 versus RW3; (c) RW2 versus RW3.Red triangles, Panthera tigris; yellow circles, Panthera pardus; cyan square, Neofelis nebulosa and Neofelis diardi; black cross, the studied fossil felid teeth. (d) the shape of fossil p4; (e) thin-plate spline deformation grid depicting shape variation along RW1 in a positive direction which explains $59.58 \%$ variance, (f) thin-plate spline deformation grid depicting shape variation along RW2 in a positive direction explaines $22.6 \%$ variance; (g) thin-plate spline deformation grid depicting shape variation along RW3 in a positive direction explains $4.77 \%$ variance.

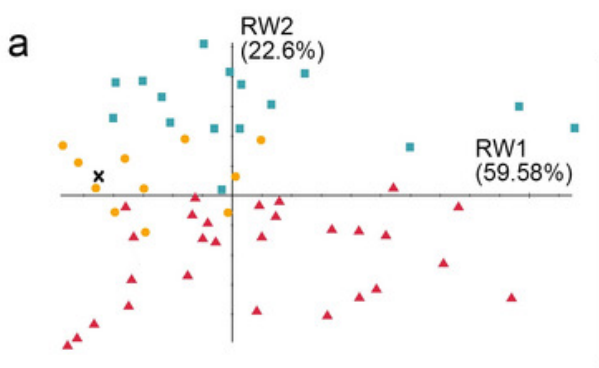

d

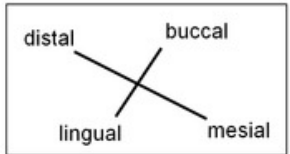

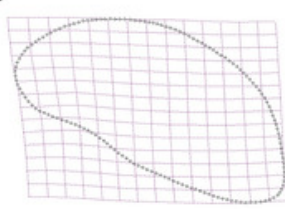

Fossil m1

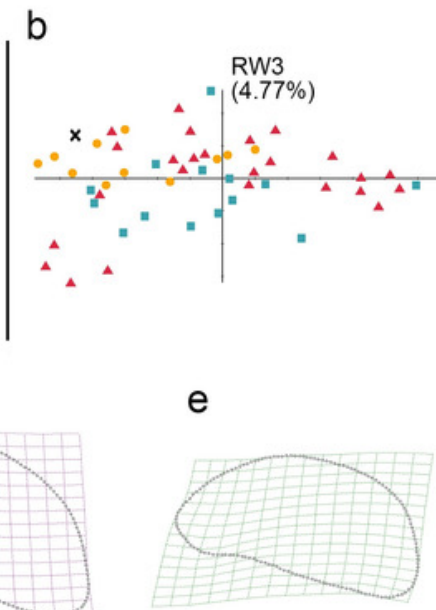

RW1

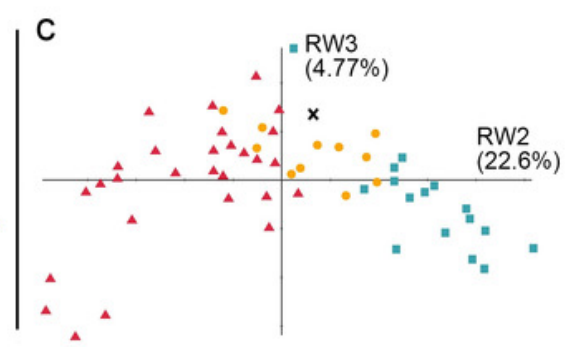

f

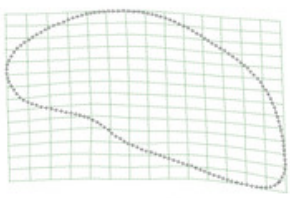

RW2 g

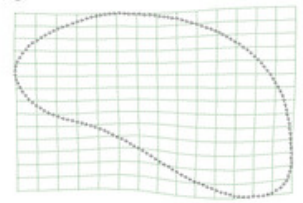

RW3 


\section{Figure 10}

Discovery sites of Pleistocene leopard fossils in East Asia

Discovery sites of Pleistocene leopard fossils in East Asia. Early Pleistocene 1, Zhen'an, Shaanxi Province, China (Li \& Deng, 2003); 2, Bailong Cave, Yunxi, Hubei Province, China (Wu et al., 2009); 3, Longgupou, Wushan County, Chongqing, China (Jin et al., 2008); 4, Cili County, Hunan Province, China (Wang et al., 1982); 5, Hezhang County, Guizhou Province, China (Zhao et al., 2013); 6, Yuanmou, Yunnan Province, China (You \& Qi, 1973); Middle Pleistocene 7, Chaoxian, Anhui Province, China (Xu et al., 1984); 8, Yanjinggou (formerly Yenchingkou), Chongqing, China (Young, 1935); 9, Panlong Cave, Yunfu, Guangdong Province, China (Wang et al., 1990); Late Pleistocene 10, Niuyan Cave (= Bull Eye Cave), Mentougou, Beijing, China (Deng et al., 1999); 11, Locality 1, Zhoukoudien (formerly Choukoutien), Beijing, China (Pei, 1934); 12, Locality 13, Zhoukoudien, Beijing, China (formerly Choukoutien) (Teilhard de Chardin \& Pei, 1941); 13, Anyang, Henan Province, China (Teilhard de Chardin \& Yang, 1936); 14, Gongwangling, Lantian County, Shaanxi Province, China (Hu \& Qi, 1978); 15, Yang'er Cave, Huatan County, Hunan Province, China (Wu et al., 2008); 16, Fuyan Cave, Daoxian, Hunan Province, China (Li et al., 2013); 17, Mawoukou Cave, Bijie, Guizhou Province, China (Zhao et al., 2016); 18, Heshang Cave, Fumin County, Yunnan Province, China (but possibly Middle Pleistocene; Zhang et al., 1989); 19, Liucheng Gigantopithecus Cave, Guangxi Province, China (Pei, 1987); 20, this study. 21, Lower Hamakita Formation, Honshu Island, Japan (Suzuki, 1966) 22, Chongphadae Cave, Hwangju County, Democratic People's Republic of Korea (Choe et al., 2020) 


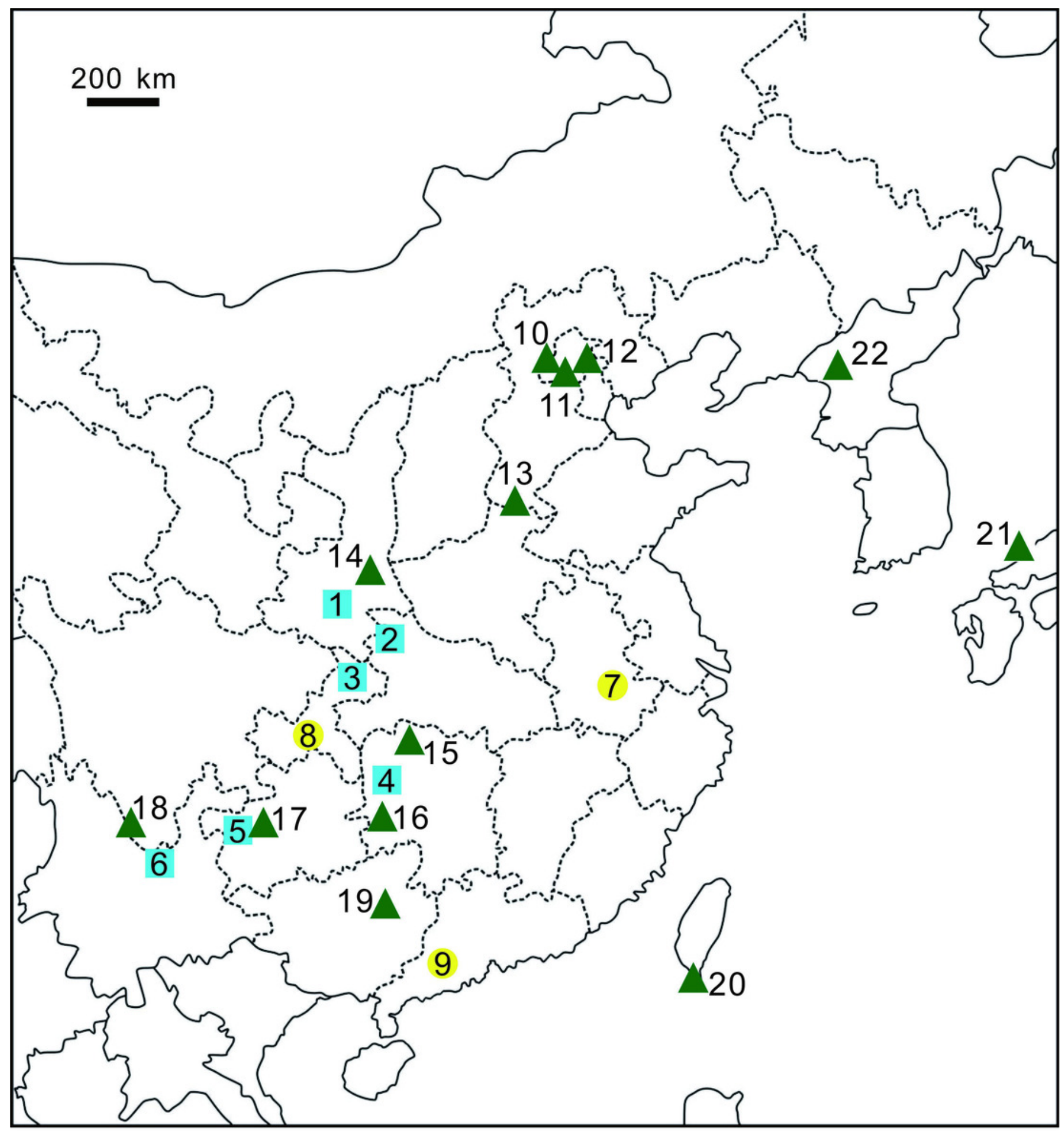

Early Pleistocene

Middle Pleistocene $\mathbf{\Delta}$ Late Pleistocene 
Table $\mathbf{1}$ (on next page)

Selected dimensions of teeth 
1 Table 1 Selected dimensions of teeth

\begin{tabular}{|c|c|}
\hline \multicolumn{2}{|c|}{ dimension } \\
\hline 1 & p3 crown length \\
\hline 2 & p3 protoconid length \\
\hline 3 & p3 protoconid height \\
\hline 4 & p3 protoconid crown width \\
\hline 5 & p4 crown length \\
\hline 6 & p4 paraconid length \\
\hline 7 & p4 paraconid crown height \\
\hline 8 & p4 paraconid crown width \\
\hline 9 & p4 potoconid length \\
\hline 10 & p4 protoconid crown height \\
\hline 11 & p4 protoconid width \\
\hline 12 & p4 hypoconid length \\
\hline 13 & p4 hypoconid height \\
\hline 14 & p4 hypoconid crown width \\
\hline 15 & m1 crown length \\
\hline 16 & m1 paraconid length \\
\hline 17 & $\mathrm{~m} 1$ paraconid height \\
\hline 18 & m1 paraconid width \\
\hline 19 & $\mathrm{~m} 1$ protoconid length \\
\hline 20 & $\mathrm{~m} 1$ protoconid height \\
\hline 21 & $\mathrm{~m} 1$ protoconid width \\
\hline
\end{tabular}


Table 2 (on next page)

Morphological comparisons of three extant species and the fossil. O, present; -, absent; $\triangle$, uncertain. 
1 Table 2 Morphological comparisons of three extant species and the fossil. ○, present; -, absent;

$2 \Delta$, uncertain.

\begin{tabular}{|c|c|c|c|c|c|}
\hline & $\begin{array}{l}\text { p3 } \\
\text { paraconid }\end{array}$ & $\begin{array}{l}\text { m1 } \\
\text { metaconid }\end{array}$ & $\begin{array}{l}\text { size } \\
\text { comparison } \\
\text { between the } \\
\text { paraconid, } \\
\text { and the } \\
\text { protoconid, of } \\
\text { m1 }\end{array}$ & $\begin{array}{l}\text { chubby } \\
\text { talonid on } \\
\text { p3 and p4 }\end{array}$ & occlusal surface \\
\hline $\begin{array}{l}\text { Longshia-dong Cave } \\
\text { fossils }\end{array}$ & o & - & similar & o & intermediate \\
\hline $\begin{array}{l}\text { Modern clouded leopards } \\
\text { (Neofelis sp.) }\end{array}$ & - & $\Delta$ & $\begin{array}{l}\text { bigger } \\
\text { protoconid }\end{array}$ & - & narrow \\
\hline $\begin{array}{l}\text { Modern tigers } \\
\text { (Panthera tigris) }\end{array}$ & o & - & similar & ○ & intermediate \\
\hline $\begin{array}{l}\text { Modern leopards } \\
\text { (Panthera pardus) }\end{array}$ & $\Delta$ & - & similar & ○ & chubby \\
\hline
\end{tabular}




\section{Table 3(on next page)}

Comparisons of dental size measurements $(\mathrm{mm})$ of Longshia-dong Cave fossil to Chinese leopard fossils (expressed by length*width). 
1 Table 3 Comparisons of dental size measurements ( $\mathrm{mm}$ ) of Longshia-dong Cave fossil to

2 Chinese leopard fossils (expressed by length $\times$ width).

\begin{tabular}{|c|c|c|c|c|c|c|c|c|c|}
\hline & \multirow{4}{*}{$\begin{array}{l}\text { Longshia-dong } \\
\text { Cave } \\
\text { (Kenting, Taiwan) }\end{array}$} & \multirow{2}{*}{\multicolumn{3}{|c|}{$\begin{array}{l}\text { Niuyan Cave } \\
\text { (Beijing, China) }\end{array}$}} & \multicolumn{2}{|c|}{ Zhoukoudian } & \multirow{2}{*}{$\begin{array}{l}\text { Gongwangling } \\
\text { (Shaanxi, China) }\end{array}$} & \multicolumn{2}{|c|}{ recent } \\
\hline & & & & & \multicolumn{2}{|c|}{ (Beijing, China) } & & & \\
\hline & & V11799 & V11800 & V11801 & location & location & V2980 & & \\
\hline & & & & & 1 st & 13 th & & & \\
\hline p3 & $12.5 \times 6.39$ & $13.4 \times 6.5$ & - & - & $16.3 \times 9$ & $16 \times 7.5$ & $14.4 \times 8$ & $14.8 \times 7.9$ & $12 \times 6.3$ \\
\hline $\mathrm{p} 4$ & $17.49 \times 8.51$ & $18.2 \times 9.7$ & $18.5 \times 9.5$ & - & $23.2 \times 12$ & $21 \times 10$ & $21 \times 11.2$ & $22.3 \times 11$ & $18 \times 9.4$ \\
\hline $\mathrm{m} 1$ & $16.77 \times 7.95$ & $19.3 \times 9.2$ & $19.8 \times 8.5$ & $19.5 \times 8.5$ & $24 \times 12.2$ & $21 \times 10$ & $22.2 \times 12$ & $22.7 \times 12.3$ & $18.3 \times 8.6$ \\
\hline
\end{tabular}

